\title{
DEFORMATION OF STEEL-BAMBOO COMPOSITE BEAM CONSIDERING THE EFFECT OF INTERFACIAL SLIPPAGE
}

\author{
J.L. Zhang ${ }^{1}$, Y.S. Li ${ }^{2, *}$, K.T. Tong ${ }^{3}$, J. Guo ${ }^{4}$ and P. Wu ${ }^{5}$ \\ 1. Ph.D. Candidate, Department of Civil Engineering, Ningbo University, Ningbo, China \\ 2. Professor of Civil Engineering, Department of Civil Engineering, Ningbo University, Ningbo, China \\ 3. Ph.D. Candidate, Department of Civil Engineering, Ningbo University, Ningbo, China \\ 4. Graduate Student, Department of Civil Engineering, Ningbo University, Ningbo, China \\ 5. Graduate Student, Department of Civil Engineering, Ningbo University, Ningbo, China \\ *(Corresponding author: E-mail:lys0451@163.com)
}

Received: 23 February 2017; Revised: 28 February 2017; Accepted: 25 June 2017

\begin{abstract}
Steel-bamboo composite beams were fabricated with cold-formed thin-walled steel and bamboo plywood bonded by structural adhesive. Six specimens were tested to investigate the effect of the steel-bamboo interfacial slippage on the deformation of the composite beams. Assuming interfacial shear force is proportional to the slippage; differential equations were established to relate deformation with the arbitrary loads, based on the elementary beam theory, and the differential relationship between the interfacial slippage and the strain. The mid-span deflection equations were derived considering the slipping effects of three common load cases. Comparing the theoretical deflections with and without the effect of slippage to the experimental results, the accuracy was improved by $7 \%$. It was found that the interfacial bond stiffness has significant influence on the deformation of the steel-bamboo composite beams. When bond stiffness was up to a value of $700 \mathrm{~N} / \mathrm{mm}$, it could ensure a reliable composite bonding between the steel and the bamboo plywood. The finite-element software ANSYS was then employed to validate the analytical results. Spring elements COMBIN39 were used to model the interfacial adhesive. The results were in good agreement with those obtained from the experimental and theoretical analyses.
\end{abstract}

Keywords: Steel-bamboo composite beam, interfacial slippage, static test, theoretical analysis, finite element analysis

DOI: $10.18057 /$ IJASC.2018.14.3.1

\section{INTRODUCTION}

Bamboo is well-known for its high strength, light weight, great stiffness, and especially for its environmental friendly features [1-2]. Research shows that bamboo improves the natural surrounding environment during its growth, consumes little energy in the manufacturing process, and it is bio-degradable at its end-of-life [3]. Thanks to the development of modern industrial technology, the original bamboo can be manufactured into plywood with fine cross-section and stable mechanical properties after a series of physical and chemical processing. The tensile strength of plywood is 2 times higher than common timbers, as the compressive strength is about 1.5 times [4], so that bamboo can be applied in the construction of modern buildings [5] and bridges [6], with advantages in environmental protection, energy saving and excellent performance in resisting earthquake due to lightweight [7].

Cold-formed thin-wall steel has advantages in material conservation and flexible modeling [8]. Comparing with the normal steel structure, cold-formed steel with the same sectional area has larger radius of gyration and moment of inertia. However, as the ratio of width to thickness increases, global instability and local buckling are more likely to occur in cold-formed steel. Thus, the load bearing capacity is primarily determined by local buckling and instability. If the stability problems could be effectively solved or alleviated, the economic efficiency would be further 
improved, and its potential applications would be widened.

In order to better take advantage of the mechanical properties of bamboo and cold-formed steel, the research group at Ningbo University put forward innovative steel-bamboo composite structures, which consist of thin-walled cold-formed steel and bamboo plywood [9]. The steel-bamboo composites can avoid the difficulties of using original bamboo to form sections of hollow shape, I-shape and box shape etc. Meanwhile, the bamboo braces the cold-formed steel sheet, which could effectively reduce its tendency of buckling, so that bamboo and cold-formed steel are well complementary to each other.

In the steel-bamboo composites, cold-formed steel and bamboo plywood are bonded with structural adhesive, which ensures the two materials work together. Since 2005, the research group has developed different kinds of steel-bamboo composite structural components, such as composite columns [10-11], composite beams [12-13], composite slabs [14-15], composite walls [16-17] and composite joints [18-19]. Lab testing on composite beams shows they exhibit high load bearing capacities and a desirable property of ductility. Thus, the effective control on the deformation of steel-bamboo composite beams is of great importance to ensure the maximum effect when these structures are applied in real construction projects. As the bending moment increases, slippage at the interface would obviously affect the mechanical performances of the composite beam and lead to larger deformation. Therefore, an analysis considering the slipping effect at the interface would better reflect the actual performance of the steel-bamboo composite beams.

The study focuses on the deformation of I-shaped steel-bamboo composite beams considering the slipping effect at the steel bamboo interface. The deformation formula was derived, and one-dimensional non-linear spring element was employed to simulate the steel-bamboo interfacial slippage using ANSYS. Experimental results, theoretical analyses and finite element simulations were compared in this study.

\section{EXPERIMENTS OF COMPOSITE BEAMS UNDER STATIC LOADING}

\subsection{Specimens}

Six steel-bamboo composite beams with a typical I-section were prepared for the lab testing and were denoted as B-1 B-6. The shear span ratios of the specimens were all greater than 3 and the failure of these specimens was caused by the bending moment. As shown in Figure 1, the steel-bamboo composite beams were made of three bamboo plywood panels and two thin-walled steel sheets which were first cold formed to the channel shape. The effective lengths of the specimens were all $2300 \mathrm{~mm}$. The variables of the specimens, including the flange width of bamboo panel, and the height of cold-formed thin-walled steel sheet, are listed in Table 1.

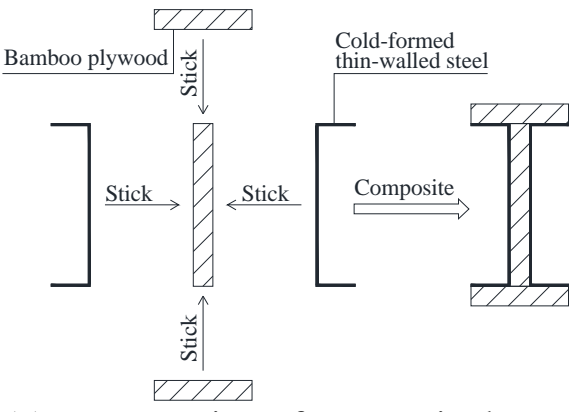

(a) cross-section of composite beam 


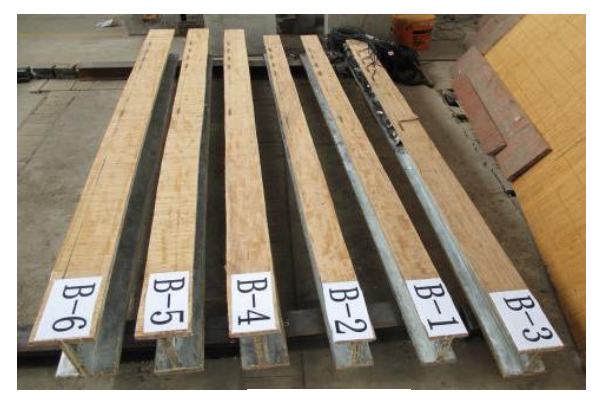

(b) specimens

Figure 1. Bamboo-steel Composite Beams

\subsection{Material Testing and Properties}

According to GB/T 228-2010, Metal Material Tensile Testing, the modulus of elasticity, yield strength and tensile strength of cold-formed thin-walled steel were measured in the lab. The modulus of elasticity and flexural strength of bamboo panel were measured based on GB/T 20241-2006, Laminated Veneer Lumber. All the mechanical properties of materials above were listed in Table 1.

\subsection{Loading and Tests}

All the specimens and tests were carried out in the Civil Engineering laboratory at the Ningbo University, China. The specimen was placed on the universal test machine with four axes and a compressive load was applied to the center of an auxiliary beam through a jack (Figure 2). The loading points and support regions were strengthened using steel plates with the thickness of 5mm to avoid local damages. The loading was force controlled. Each stage of loading was $3 \mathrm{kN}$ for $\mathrm{B}-1 \sim \mathrm{B}-3$ and $6 \mathrm{kN}$ for B-4 B-6. In order to measure the deflection of composite beam under different loadings, the extensometers were deployed at the supports, mid-span and loading point of the composite beam, respectively (Figure 2).

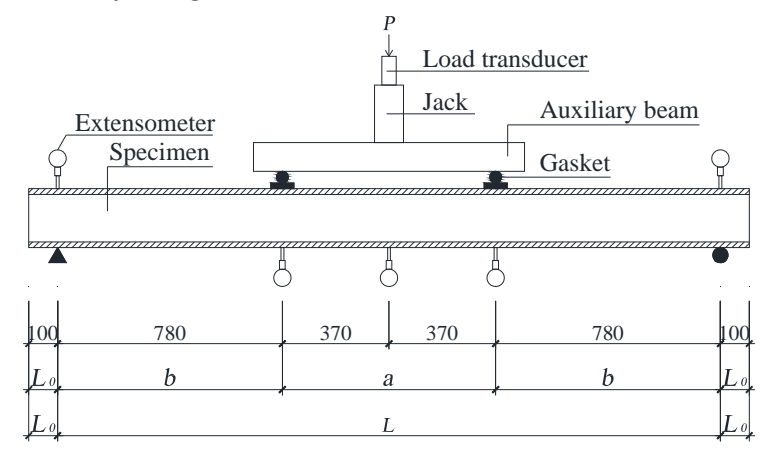

Figure 2. Scheme of Loading Apparatus

\subsection{Testing Results and Analysis}

The experimental results indicated that the steel-bamboo composite beams had good load bearing capacities and large deformation before failure. According to the steel structures design codes (GB 50017-2003) and the timber design codes (GB 50005-2013) in China, the deformation should be limited to $l / 250$ ( $l$ is the effective span). The experimental data denoted that the strains of steel and bamboo panel were in elastic state and the load vs mid-span deflection curve presented linear property when the mid-span deflection was less than $l / 250$ as shown in Figure 3. 
Table1. Parameters of Specimens

\begin{tabular}{|c|c|c|c|c|c|c|c|c|c|c|c|}
\hline Number & $\begin{array}{c}\text { Thickness } \\
\text { (Bamboo } \\
\text { Panel) } \\
\text { /mm }\end{array}$ & $\begin{array}{c}\text { Thickness } \\
\text { (Steel Sheet) } \\
\text { /mm }\end{array}$ & $\begin{array}{l}\text { I-section } \\
\text { /mm }\end{array}$ & $\begin{array}{l}\text { Members } \\
\text { /mm }\end{array}$ & $\begin{array}{l}\text { MOE } \\
\text { (Bamboo } \\
\text { Panel) } \\
\text { /Mpa }\end{array}$ & $\begin{array}{c}\text { Flexure } \\
\text { Strength } \\
\text { (Bamboo } \\
\text { Panel)/ Mpa }\end{array}$ & $\begin{array}{l}\text { MOE } \\
\text { ( Steel } \\
\text { Sheet) } \\
\text { /Mpa }\end{array}$ & $\begin{array}{c}\text { Flexure } \\
\text { Strength } \\
\text { ( Steel Sheet) } \\
\text { / Mpa }\end{array}$ & $\begin{array}{c}\text { Tensile } \\
\text { Strength } \\
\text { (Steel } \\
\text { Sheet)/ Mpa }\end{array}$ & $\begin{array}{c}\text { Distance } \\
\text { between } \\
\text { Symmetric } \\
\text { Point Loads } \\
a / \mathrm{mm} \\
\end{array}$ & $\begin{array}{c}\text { Shear } \\
\text { Span } \\
\text { Ratio } \\
b / h\end{array}$ \\
\hline B-1 & 15.0 & 1.5 & $30.0 \times 124.0 \times 30.0$ & $79.0 \times 154.0$ & 8500 & 73 & 200000 & 245 & 340 & 740 & 5.06 \\
\hline B-2 & 17.0 & 1.5 & $30.0 \times 124.0 \times 30.0$ & $99.0 \times 158.0$ & 6500 & 62 & 200000 & 245 & 340 & 740 & 4.94 \\
\hline B-3 & 17.0 & 2.0 & $40.0 \times 124.0 \times 40.0$ & $99.0 \times 158.0$ & 6500 & 62 & 200000 & 270 & 340 & 740 & 4.94 \\
\hline B-4 & 17.0 & 2.0 & $40.0 \times 165.0 \times 40.0$ & $99.0 \times 199.0$ & 6500 & 62 & 200000 & 270 & 340 & 740 & 3.92 \\
\hline B-5 & 19.0 & 2.0 & $40.0 \times 165.0 \times 40.0$ & $99.0 \times 203.0$ & 6900 & 67 & 200000 & 270 & 340 & 740 & 3.84 \\
\hline B-6 & 19.0 & 2.0 & $50.0 \times 165.0 \times 50.0$ & $119.0 \times 203.0$ & 6900 & 67 & 200000 & 270 & 340 & 740 & 3.84 \\
\hline
\end{tabular}

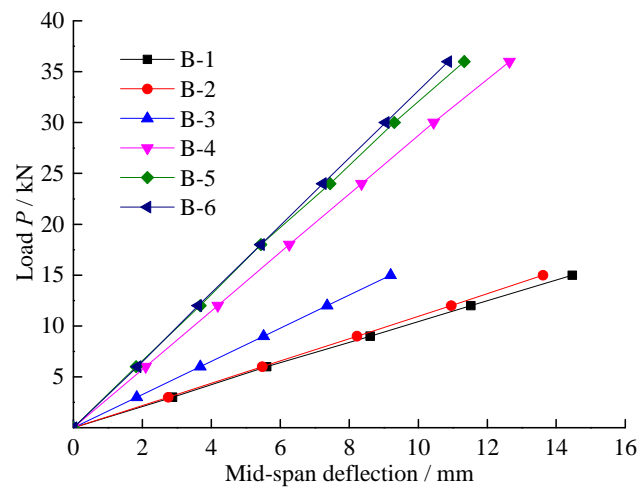

Figure 3. Load vs. Mid-span Deflection Curves of Composite Beam

The steel-bamboo interfacial slippage caused by the shear stress at the bonding interface was observed in the tests. The slippage could also be obtained by analyzing the strain distribution in steel-bamboo interface and the strain differences. The effects of the slippage on the deformation of the steel-bamboo composite beams were summarized as follows: (1) the strain in the section is no longer consistent with the assumption of plane section due to the strain changes at the interface. (2) The mid-span deflection increased due to the reduced stiffness of the composite beam. Therefore, the interfacial slipping effect should be considered in the deformation analysis of the steel-bamboo composite beams.

\section{THEORETICAL APPROACH}

\subsection{Basic Assumptions}

In this analysis, the following assumptions were made for the composite beams: (1) the cold-formed thin-walled steel and bamboo plywood are all linear elastic. (2) The relationship between the shear stress at the bonding interface and the slippage is considered, i.e. $Q=k \cdot s$. Here, $Q$ is the shear stress, $s$ is the slippage and $k$ denotes the interfacial bond stiffness as reported in Ref. [20]. The interfacial shear stress equations can be expressed as: $Q_{1}=k \cdot s_{1}$ (compressive region) and $Q_{2}=k \cdot s_{2}$ (tensile region), when the same stiffness $k$ is assumed for the compressive and tensile regions. $Q_{1}$ and $Q_{2}$ are the shear stresses at the bonding interfaces of the compressive and tensile region, while $s_{1}$ and $s_{2}$ are the interfacial slippages in the compressive and tensile regions respectively. (3) The strain distributions of cold-formed thin-walled steel and bamboo plywood in the direction of height are both assumed to be linear. (4) No interfacial 
slippage is allowed in the web of the steel-bamboo composite beams. (5) The shear deformation and interfacial uplifting force are neglected.

\subsection{Differential Equations}

Three differential segments of the composite beams are shown in Figure 4, which include the top flange, the web and the bottom flange and are denoted as 1, 2, 3, respectively. According to the equilibrium conditions of the differential segments, the following differential equations can be derived:

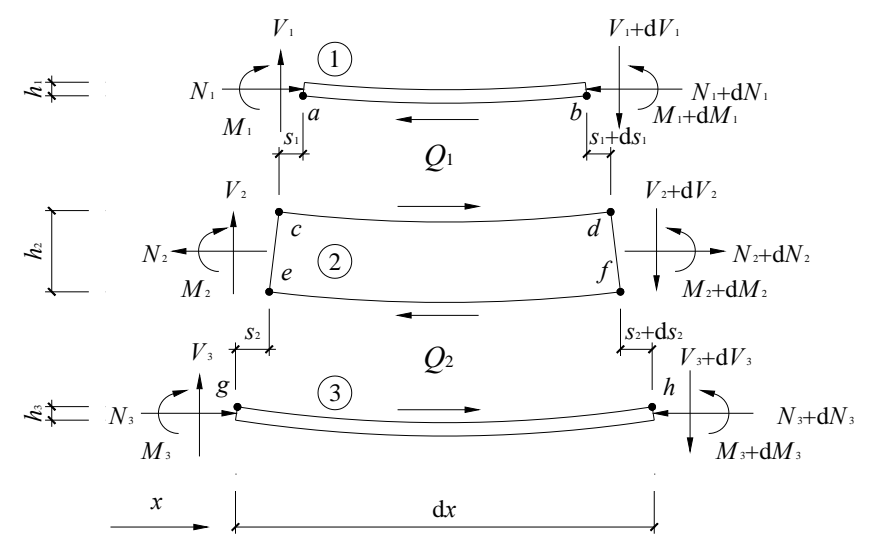

Figure 4. Load State of Micro Element

$$
\begin{aligned}
& \mathrm{d} M_{1}-V_{1} \mathrm{~d} x-\frac{1}{2} Q_{1} h_{1} \mathrm{~d} x=0 \\
& \mathrm{~d} M_{2}-V_{2} \mathrm{~d} x-\frac{1}{2} Q_{1} h_{2} \mathrm{~d} x-\frac{1}{2} Q_{2} h_{2} \mathrm{~d} x=0 \\
& \mathrm{~d} M_{3}-V_{3} d x-\frac{1}{2} Q_{2} h_{3} \mathrm{~d} x=0
\end{aligned}
$$

where $M_{1}, M_{2}$ and $M_{3}$ are the bending moments of the three differential segments respectively. $V_{1}$, $V_{2}$ and $V_{3}$ are the shear forces of the three differential segments respectively. $h_{1}, h_{2}$ and $h_{3}$ are the section heights of the three differential segments respectively.

Solving from Eqs. 1, 2 and 3.

$\frac{\mathrm{d} M_{1}}{\mathrm{~d} x}+\frac{\mathrm{d} M_{2}}{\mathrm{~d} x}+\frac{\mathrm{d} M_{3}}{\mathrm{~d} x}-V-Q_{1} Z_{1}-Q_{2} Z_{2}=0$

where $Z_{1}=\left(h_{1}+h_{2}\right) / 2 ; \quad Z_{2}=\left(h_{2}+h_{3}\right) / 2 ; \quad V=V_{1}+V_{2}+V_{3}$.

Eq. 5 can be obtained based on the general beam theory and assumption of small deformation:

$\phi=-\frac{\mathrm{d}^{2} y}{\mathrm{~d} x^{2}}=\frac{M_{1}}{E_{1} I_{1}}=\frac{M_{2}}{E_{2} I_{2}}=\frac{M_{3}}{E_{3} I_{3}}$

where $\phi$ and $y$ are the curvature, and the distance from the neutral axis of cross section to any point of interest, respectively. $E_{\mathrm{i}}$ and $I_{\mathrm{j}}$ are the modulus of elasticity, and the second moment of area, respectively. The subscript $i$ and $j$ represent the number of the three differential segments $(i, j=1,2,3)$. 
According to the differential relationships between the interfacial slippage and strain differences in the compressive and tensile regions, the following equilibrium equations can be derived as

$$
\begin{aligned}
& \frac{\mathrm{d} s_{1}}{\mathrm{~d} x}=\varepsilon_{a b}-\varepsilon_{c d}=\phi\left(\frac{h_{1}}{2}+\frac{h_{2}}{2}\right)-\left(\frac{N_{1}}{E_{1} A_{1}}+\frac{N_{2}}{E_{2} A_{2}}\right)=\phi Z_{1}-\left(\frac{N_{1}}{E_{1} A_{1}}+\frac{N_{2}}{E_{2} A_{2}}\right) \\
& \frac{\mathrm{d} s_{2}}{\mathrm{~d} x}=\varepsilon_{e f}-\varepsilon_{g h}=\phi\left(\frac{h_{2}}{2}+\frac{h_{3}}{2}\right)+\left(\frac{N_{3}}{E_{3} A_{3}}+\frac{N_{2}}{E_{2} A_{2}}\right)=\phi Z_{2}+\left(\frac{N_{3}}{E_{3} A_{3}}+\frac{N_{2}}{E_{2} A_{2}}\right)
\end{aligned}
$$

where $N_{\mathrm{i}}$ and $A_{\mathrm{i}}$ are the axial force and cross-sectional area of the three differential segments respectively.

Solving from Eqs. 4 and 5

$\frac{\mathrm{d}^{3} y}{\mathrm{~d} x^{3}}+\frac{V}{E I}+\frac{Z_{1}}{E I} Q_{1}+\frac{Z_{2}}{E I} Q_{2}=0$

where $E I=E_{1} I_{1}+E_{2} I_{2}+E_{3} I_{3}$. If we take the derivative of Eq. 8 with respect to $x$, we obtain

$\frac{\mathrm{d}^{4} y}{\mathrm{~d} x^{4}}+\frac{1}{E I} \cdot \frac{\mathrm{d} V}{\mathrm{~d} x}+\frac{\mathrm{d} Q_{1}}{\mathrm{~d} x} \cdot \frac{Z_{1}}{E I}+\frac{\mathrm{d} Q_{2}}{\mathrm{~d} x} \cdot \frac{Z_{2}}{E I}=0$

where $\frac{\mathrm{d} V}{\mathrm{~d} x}=-P(x)$.

Substituting Equations $Q_{1}=k \cdot s_{1}$ and $Q_{2}=k \cdot s_{2}$ in Eq. 9 results:

$\frac{\mathrm{d}^{4} y}{\mathrm{~d} x^{4}}-\frac{1}{E I} P(x)+k \frac{\mathrm{d} s_{1}}{\mathrm{~d} x} \cdot \frac{Z_{1}}{E I}+k \frac{\mathrm{d} s_{2}}{\mathrm{~d} x} \cdot \frac{Z_{2}}{E I}=0$

Substitution of Eqs. 5 and 6 into Eq. 10 gives the following governing differentiate equation:

$\frac{\mathrm{d}^{4} y}{\mathrm{~d} x^{4}}-\left(k \frac{Z_{1}^{2}}{E I}+k \frac{Z_{2}^{2}}{E I}\right) \frac{\mathrm{d}^{2} y}{\mathrm{~d} x^{2}}-\frac{k Z_{1}}{E I} \cdot \frac{N_{1}}{E_{1} A_{1}}-\frac{k Z_{1}}{E I} \cdot \frac{N_{2}}{E_{2} A_{2}}+\frac{k Z_{2}}{E I} \cdot \frac{N_{2}}{E_{2} A_{2}}+\frac{k Z_{2}}{E I} \cdot \frac{N_{3}}{E_{3} A_{3}}=\frac{P(x)}{E I}$

In this study, the same top and bottom flange of the composite beam is considered, i.e.

$Z_{1}=Z_{2}=Z$

Based on the section equilibrium of the composite beam, the governing differential equation is given as below:

$-E I y^{\prime \prime}=M-N_{1} Z+N_{3} Z$

where $M$ is the bending moment in the section of the composite beam. 
Substitution of Eqs. 12 and 13 into Eq. 11 gives:

$\frac{\mathrm{d}^{4} y}{\mathrm{~d} x^{4}}-\alpha^{2} \frac{\mathrm{d}^{2} y}{\mathrm{~d} x^{2}}=y_{0}(x)$

where $\alpha^{2}=k\left(\frac{2 Z^{2}}{E I}+\frac{1}{A_{0} E_{0}}\right), y_{0}(x)=\frac{1}{E I}\left(P(x)+\frac{k M}{A_{0} E_{0}}\right)$.

\subsection{Solution of the Mid-span Deflection}

The mid-span deflection of a composite beam subjected to two symmetric point loads are derived in this study. Setting the origin of coordinate at the mid-span of the composite beam, the bending moment of the beam can be expressed as:

In the pure bending zone:

$M=P\left(\frac{L}{2}-\frac{a}{2}\right) x \in\left[-\frac{a}{2}, \frac{a}{2}\right]$

In the shear and bending zone:

$M=P\left(\frac{L}{2}-x\right) \quad x \in\left[\frac{a}{2}, \frac{L}{2}\right]$

$M=P\left(\frac{L}{2}+x\right) \quad x \in\left[-\frac{L}{2},-\frac{a}{2}\right]$

where $L, a, P$, and $M$ denote the span length, the distance between two point loads (Figure 2), the magnitude of the point load, and the bending moment in the cross section, respectively.

Because of the symmetry, only half of the beam in $[0, L / 2]$ is considered. The deflection equations need to be determined by applying suitable boundary conditions:

$y_{x=L / 2}=0 ; \quad y_{x=0}^{\prime \prime}=0 ; \quad y_{x=L / 2}^{\prime \prime}=0$

Solving Eq. 14 according the boundary conditions gives the deflection equations:

In the pure bending zone:

$y_{p b}=\frac{P}{48 E I}\left(2 L^{3}+a^{3}-3 L a^{2}\right)-\frac{P}{2 E I \alpha^{2}}(L-a)-\frac{P\left(\mathrm{e}^{\alpha L}-\mathrm{e}^{\alpha a}\right)}{E I \alpha^{3}\left(\mathrm{e}^{\alpha L}+\mathrm{e}^{\alpha a}\right)}+\frac{P}{4 E I} x^{2}(a-L)$

In the shear and bending zone:

$y_{s b}=\frac{P}{48 E I}\left(2 L^{3}-3 L a^{2}-\frac{24}{\alpha^{2}} L+\frac{48+6 a^{2} \alpha^{2}}{3 \alpha^{3}}(L-a)+\frac{48\left(\mathrm{e}^{\alpha L-\alpha x}-\mathrm{e}^{\alpha x}\right)}{\alpha^{3}\left(\mathrm{e}^{\frac{1}{2} \alpha a}+\mathrm{e}^{\alpha L-\frac{1}{2} \alpha a}\right)}+\frac{P}{12 E I} x^{3}(2 x-3 L)\right.$

The mid-span deflection is given by:

$y_{m, s}=\frac{P}{48 E I}\left(2 L^{3}+a^{3}-3 L a^{2}\right)-\frac{P}{2 E I \alpha^{2}}(L-a)-\frac{P\left(\mathrm{e}^{\alpha L}-\mathrm{e}^{\alpha a}\right)}{E I \alpha^{3}\left(\mathrm{e}^{\alpha L}+\mathrm{e}^{\alpha a}\right)}$ 
The last two items in Eq. 15 are the additional deflections caused by the slipping effect. The expression for mid-span deflection in a composite beam subjected to a central point load and uniformly distributed load can be determined based on the method discussed above.

The composite beam is subjected to a central point load:

$$
y_{m, c}=\frac{P}{E I}\left[\frac{L^{3}}{48}-\frac{L}{4 \alpha^{2}}+\frac{\mathrm{e}^{\alpha L}-1}{2 \alpha^{3}\left(\mathrm{e}^{\alpha L}+1\right)}\right]
$$

The composite beam is subjected to a uniform load:

$$
y_{m, u}=\frac{q}{E I}\left[\frac{5 L^{4}}{384}-\frac{L^{2}}{8 \alpha^{2}}+\frac{\left(\mathrm{e}^{\frac{1}{2} \alpha L}-1\right)^{2}}{\alpha^{4}}\right]
$$

\subsection{Test Verification}

\subsubsection{Comparison of Mid-span Deflection}

To verify the analytical model, the theoretical calculation results are compared with the experimental data. The load vs. mid-span deflection curves of the composite beams are shown in Figure 5. It can be seen that the theoretical solutions show a good agreement with the experimental data. Table 2 compares the mid-span deflections from the experiments and the theoretical calculation in the serviceability limit state. It is found that the calculations from the analytic model are in good agreement with the corresponding measurements and the average errors are less than $10 \%$ except B-6. The theoretical values of B-1 B-5 are lower than the experimental data due to the shear deformation and the weight of auxiliary beam, etc. The error of B-6 is larger and this is mainly triggered by the following factors: (1) the bonding at the interface between steel and bamboo may not be uniform. (2) there may be vertical disturbances at the extensometers during loading process.

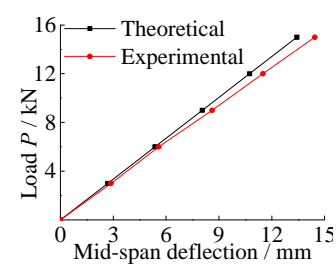

(a) B-1

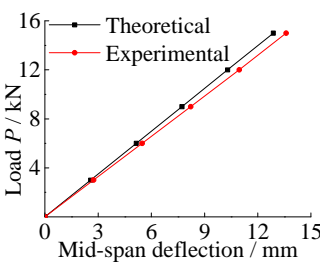

(b) B-2

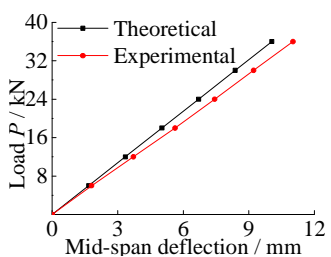

(c) B-4

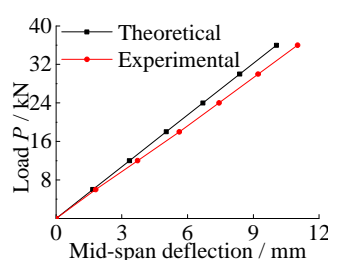

(d) B-5

Figure 5. Load vs. Mid-span Deflection Curves of Composite Beam

\subsubsection{Effect of the slippage}

In order to explore the effect of the steel-bamboo interfacial slippage on the deformation of composite beam, the mid-span deflection has been predicted without considering the slipping effect using the following equation [21]:

$y_{m}=P(L-a) \frac{2 L^{2}+2 L a-a^{2}}{48 E_{s} I_{s B}}$

where $y_{\mathrm{m}}, E_{S}$ and $I_{S B}$ denote the mid-span deflection without considering the slipping effect, the modulus of elasticity of cold-formed thin-walled steel, and the second moment of area respectively. The theoretical calculations are compared with experimental results in Table 2. 
Table 2. Mid-span Deflection Results by Calculation

\begin{tabular}{ccccccc}
\hline Number & $\begin{array}{c}\text { Loading } \\
/ \mathrm{kN}\end{array}$ & $\begin{array}{c}\text { Experiments } \\
y_{1} / \mathrm{mm}\end{array}$ & $\begin{array}{c}\text { Predictions } \\
y_{\mathrm{m}, \mathrm{s}} / \mathrm{mm}\end{array}$ & $\begin{array}{c}\text { Predictions } \\
y_{\mathrm{m}} / \mathrm{mm}\end{array}$ & $\begin{array}{c}\text { Error } \\
\delta_{1} / \%\end{array}$ & $\begin{array}{c}\text { Error } \\
\delta_{2} / \%\end{array}$ \\
\hline $\mathrm{B}-1$ & 12 & 11.49 & 10.74 & 9.51 & 6.53 & 17.23 \\
$\mathrm{~B}-2$ & 12 & 10.95 & 10.30 & 9.23 & 5.94 & 15.71 \\
$\mathrm{~B}-3$ & 15 & 9.19 & 8.33 & 7.66 & 9.36 & 16.65 \\
$\mathrm{~B}-4$ & 30 & 9.21 & 8.38 & 7.90 & 8.79 & 13.10 \\
$\mathrm{~B}-5$ & 30 & 9.30 & 8.40 & 7.92 & 9.68 & 14.84 \\
$\mathrm{~B}-6$ & 36 & 10.78 & 8.85 & 8.36 & 17.90 & 22.45 \\
\hline
\end{tabular}

Note: The value of $y_{\mathrm{m}, \mathrm{s}}$ is calculated by Eq. 15 and $y_{\mathrm{m}}$ is calculated by Eq. 18. The values of error $\delta$ can be obtained by the following equations.

$$
\delta_{1}=\left|\frac{y_{1}-y_{m}}{y_{1}}\right| \times \% \quad \delta_{2}=\left|\frac{y_{1}-y_{m, s}}{y_{1}}\right| \times \%
$$

It can be seen that the average error $\delta_{2}$ without considering the slipping effect is $15.5 \%$ and the calculation accuracy of Eq. 15 is about 4.4\% 10.7\% higher than that of Eq. 18. The ratio between additional deflection due to the interface slippage and the global deflection significantly increases with the increased load. The superiority of the analytical model considering the slipping effect becomes more apparent.

\subsubsection{Effect of the bond stiffness}

Eq. 15 can be expressed in terms of the load $P$, the bending stiffness $E I$ and the interface bond stiffness $k$ and so on, i.e. $y=f(P, E I, k \ldots)$. The mid-span deflection vs. interface stiffness curves of the composite beams B-1 B-3 are illustrated in Figure 6. It is revealed that the interface bond stiffness $(0 \leq k \leq 700 \mathrm{~N} / \mathrm{mm})$ has significant influences on the mid-span deflection. When $k=0$, the ratio between the additional deflection and the global deflection is around $25 \%$. When $k>700 \mathrm{~N} / \mathrm{mm}$, the sensitivity of mid-span deflection to the interface bond stiffness is low. Therefore, the additional deflection caused by the slipping effect cannot be neglected for the interface bond stiffness $k$ of the steel-bamboo composite beam, which is typically around $425 \mathrm{~N} / \mathrm{mm}$ measured in the lab testing. The interface bond stiffness of the composite beam must meet certain requirements to ensure sufficient structural integrity.

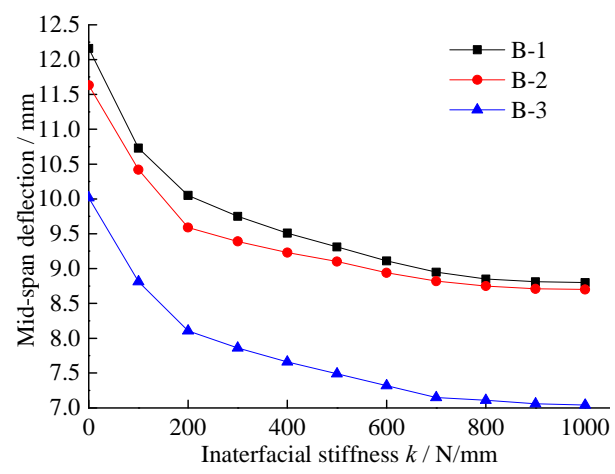

Figure 6. Mid-span Deflection vs. Interface Stiffness $k$ Curves 


\section{FINITE ELEMENT NUMERICAL SIMULATION}

\subsection{Modeling}

In this section, a finite element model using ANSYS 11.0 was established to predict the mid-span deflection of the steel-bamboo composite beam. In the model, the shell element (SHELL63), the solid element (SOLID45) and the one-dimensional nonlinear spring element (COMBIN39) were adopted to simulate the cold-formed thin-walled steel, the bamboo panel and the steel-bamboo interfacial slippage, receptively. The properties of the component materials used in the numerical analysis are listed in Table 1 and the spring stiffness can be calculated according to Ref. [20].

\subsection{Numerical Simulations}

The establishment and solution of the finite element model of steel-bamboo composite beam are summarized as follows:

(1) By choosing appropriate element types and material properties, and setting corresponding real constants and key options, finite element models of cold-formed thin-walled steel and bamboo plywood were established respectively, as well as the meshes, shown in Figure 7 (a) and (b).

(2) To minimize the discrepancies between the numerical results and the actual situations, gaskets with infinite stiffness were employed at the loading points and the bearings, to avoid the stress concentrations.

(3) Spring elements were generated and particular nodes were coupled, shown in Figure 7 (c). Under the loading, slippages at the composite beam's web were relatively small, which was neglected, thus node coupling were applied in three dimensions (longitudinal, transverse and normal) on steel and bamboo elements of the web. Vertical lift was not found at the flange in the serviceability limit state, and it can be considered that the stiffness of the flange in the vertical direction is infinite. Nodes at the contact interface between flange and web were coupled in tangential and normal directions and spring element were generated in the vertical direction.

(4) Symmetric point loads were applied and numerical solutions were obtained, deformation is presented in Figure 7 (d).

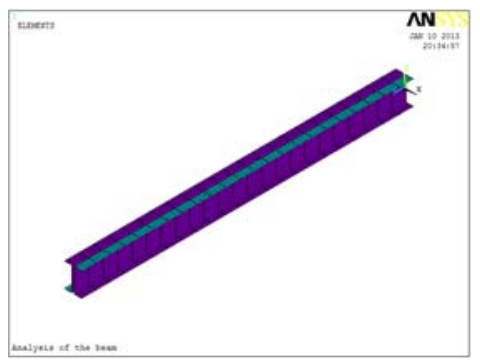

(a) cold-formed thin-walled steel

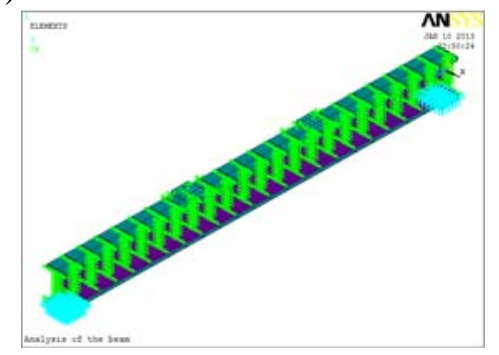

(c) node coupling

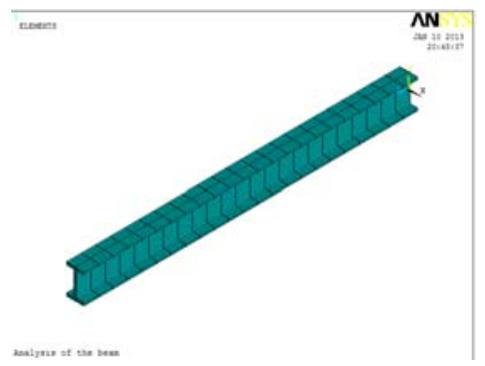

(b) bamboo plywood

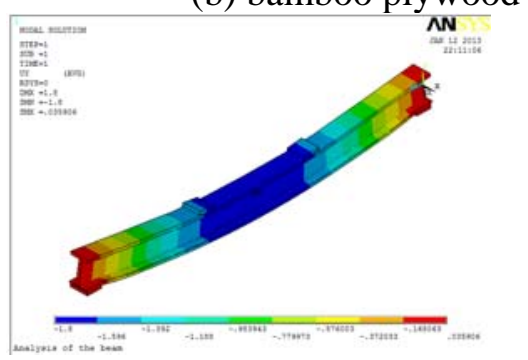

(d) deformation

Figure 7. Finite Element Model 


\subsection{Numerical Results}

Using the finite element method, the mid-span deflections of the composite beams are determined in ANSYS. The solutions are compared with experimental results in Table 3. It is revealed that the differences $\delta_{3}$ between the numerical and the lab testing values are small except B-6, which might be caused by the human errors during the production process and the testing process. The efficiency and feasibility of the analytical method and the finite element model are verified.

Table3. Mid-Span Deflection Results by FEM Simulation

\begin{tabular}{ccccccc}
\hline Number & $\begin{array}{c}\text { Loading/ } \\
\mathrm{kN}\end{array}$ & $\begin{array}{c}\text { Experiments } \\
y_{1} / \mathrm{mm}\end{array}$ & $\begin{array}{c}\text { Predictions } \\
y_{\mathrm{m}, \mathrm{s}} / \mathrm{mm}\end{array}$ & $\begin{array}{c}\text { FEM } \\
y_{2} / \mathrm{mm}\end{array}$ & $\begin{array}{c}\text { Ratio } \\
y_{1} / y_{2}\end{array}$ & $\begin{array}{c}\text { Error } \\
\delta_{3} / \%\end{array}$ \\
\hline $\mathrm{B}-1$ & 12 & 11.49 & 10.74 & 10.65 & 1.08 & 7.31 \\
$\mathrm{~B}-2$ & 12 & 10.95 & 10.30 & 10.42 & 1.06 & 4.84 \\
$\mathrm{~B}-3$ & 15 & 9.19 & 8.33 & 8.48 & 1.08 & 7.73 \\
$\mathrm{~B}-4$ & 30 & 9.21 & 8.38 & 8.81 & 1.05 & 4.34 \\
$\mathrm{~B}-5$ & 30 & 9.30 & 8.40 & 8.47 & 1.10 & 8.92 \\
$\mathrm{~B}-5$ & 36 & 10.78 & 8.85 & 9.28 & 1.16 & 13.91 \\
\hline
\end{tabular}

Note: The values of error $\delta_{3}$ can be obtained by the following equations.

$\delta_{3}=\left|\frac{y_{1}-y_{2}}{y_{1}}\right| \times \%$

\section{CONCLUSIONS}

The mid-span deflection of the steel-bamboo composite beam has been studied based on the steel-bamboo interfacial slipping effect. The following conclusions are drawn from a detailed analysis:

(1) Based on the shear slipping relationship $Q=k \cdot s$, and the equilibrium condition, the deformation equations of the slipping effect of the steel-bamboo composite beam under three common loading effects are established, which can be used as theoretical reference to the actual engineering applications.

(2) The theoretical results considering the slipping effect agree well with the experiment data and the average error is around $8.1 \%$. This demonstrates that the analytical method to derive the mid-span deflection of the steel-bamboo composite beam is reasonable.

(3) The average error between the theoretical values without considering the interface slipping effect and the experimental results is $15.5 \%$, and the calculation accuracy is effectively improved considering the slipping effect.

(4) The interface bond stiffness has significant influence on the deformation of the steel-bamboo composite beam. Therefore, the interface adhesive should have enough stiffness to ensure the structural integrity of the steel-bamboo composite beams.

(5) The nonlinear one-dimensional spring element COMBIN39 and the relevant element generation technologies can be used to model the bamboo-steel interface and the deformation of steel-bamboo composite beam well in ANSYS. 


\section{ACKNOWLEDGEMENTS}

The authors gratefully acknowledge the financial support provided by National Key R\&D Program of China [grant numbers 2017YFC502], the National Natural Science Foundation of China (NSFC) [grant numbers 51678310 \& 51378265], Ningbo Natural Science Foundation [grant numbers 2017A610305], and K.C. Wong Magna Fund at the Ningbo University. Special thanks are given to Dr. Rui Liu, Assistant Professor of Structures in the College of Architecture and Environmental Design, Kent State University, for his time to revise the English of the manuscript. Acknowledgment is also extended to the technical support of Civil Engineering Laboratory of Ningbo University.

\section{REFERENCES}

[1] Wang, K., Li, Q. and Gao, X., "Utilization Status and Development of Bamboo Resources”, Journal of Bamboo Research, 2000, Vol. 19, No. 4, pp. 72-75.

[2] Jain, S., Kumar, R. and Jindal, U., "Mechanical Behavior of Bamboo and Bamboo C Composite”, Journal of Materials Science, 1992, Vol. 27, No. 17, pp. 4598-4604.

[3] Xiao, Y., Yang, R., Shan, B., et al., "Experimental Research on Mechanical Properties of Glubam”, Journal of Building Structures, 2012, Vol. 33, No. 11, pp. 150-157.

[4] Zhang, X.E.J., Li, Y., et al., "Experimental Research on Compression and Flexural Mechanical Performance of Recombinant Bamboo”, Industrial Construction, 2016, Vol. 46, No. 1, pp. 7-12.

[5] Xiao, Y., Chen, G., Shan, B., et al., "Research and Applicant of Lightweight Glue-laminated Bamboo Frame Structure”, Journal of Building Structures, 2010, Vol. 31, No. 6, pp. 195-203.

[6] Xiao, Y., Zhou, Q. and Shan, B., "Design and Construction of Modern Bamboo Bridges”, Journal of Bridge Engineering, 2010, Vol. 15, No. 5, pp. 553-541.

[7] Lv, Q., Wei, Y., Zhang, Q., et al., "Key Technologies of the New Anti-seismic Model Living Room with Bamboo Engineering Materials”, Special Structures, 2008, Vol. 25, No. 4, pp 6-10.

[8] Al-Mosawi, S. and Saka, M.P., “Optimum Shape Design of Cold-formed Thin-walled Steel Sections”, Advances in Engineering Software, 2000, Vol. 31, No. 11, pp. 851-862.

[9] Li, Y. and Zhang. J., "State of the Art of Steel-bamboo Composite Components and Structural System”, Industrial Construction, 2016, Vol. 46, No. 1, pp. 1-6.

[10] Jiang, T., Li, Y., Shan, W., et al., "Seismic Behavior of Thin-waled C Steel-bamboo Plywood Composite Column”, Journal of Northeast Forestry University, 2011, Vol. 39, No. 12, pp. 82-85.

[11] Liu, T., Li, Y., Xu, K., et al., "Research on Mechanical Performance of Steel-bamboo Composite Box Short Column”, Industrial Construction, 2016, Vol. 46, No. 1, pp. 25-29.

[12] Li, Y., Shen, H., Shan, W. et al., "Experimental Study on Shear Behavior of I-shaped Section Bamboo-steel Composite Beams”, Journal of Building Structures, 2011, Vol. 32, No. 7, pp. 80-86.

[13] Li, Y., Shan, W., Shen, H., et al., "Bending Resistance of I-section Bamboo-steel Composite Beams Utilizing Adhesive Bonding”, Thin-walled Structures, 2015, Vol. 89, pp. 17-24.

[14] Li, Y., Shan, W., Huang, Z. et al., "Experimental Study on Mechanical Behavior of Profiled Steel Sheet-bamboo Plywood Composite Slabs”, Journal of Building Structures, 2008, Vol. 29, No. 1, pp. 96-102.

[15] Li, Y., Shen, H., Shan, W., et al., "Flexural Behavior of Lightweight Bamboo-steel Composite Slabs”, Thin-walled Structures, 2012, Vol. 53, pp. 83-90. 
[16] Li, Y., Guo, J., Jiang, T., et al., "Experimental Study on Seismic Behavior of Cold-formed Thin-walled C. Steel-bamboo Plywood Composite Walls”, Journal of Shenyang Jianzhu University (Natural Science), 2013, Vol. 29, No. 6, pp. 969-976.

[17] Zhang, J., Li, Y., Zhai, J., et al., "Experimental Study on Heat Transfer Behavior of Cold-formed Thin-walled Steel-bamboo Plywood Composite Walls”, Industrial Construction, 2016, Vol. 46, No. 1, pp. 13-19.

[18] Li, Y., Jiang, T., Shan, W., et al., "Quasi-static Test on Steel-bamboo Composite Beam-column Exterior Joints”, Engineering Mechanics, 2013, Vol. 30, No. 4, pp. 241-248.

[19] Li, Y., He, J., Zhang, J., et al., "Seismic Response Analysis of Bamboo-steel Composite Frame Structure based on Performance of Beam-column Joints”, Journal of Architecture and Civil Engineering, 2016, Vol. 33, No. 5, pp. 22-28.

[20] Xie, Q., "Research on Bond Property of Steel-bamboo Interface under Static Loads”, MD Thesis, Faculty of Architectural, Civil Engineering and Environment, Ningbo University, Ningbo, China, 2012.

[21] Shen, H., Li, Y., Zhang, W., et al., "Experimental Study on Flexural Behavior of Cold-formed Thin-wall Steel-bamboo Composite Beams”, Journal of Building Structures, 2009, Vol. 30, No. S2, pp. 171-175. 